\title{
Concepções Científicas: O Seriado House M.D. como propulsor de Mudanças Paradigmáticas
}

Anita Rodrigues Cordeiro

Ana Maria dos Anjos Carneiro-Leão

Zélia Maria Soares Jófili

\section{Resumo}

Os fenômenos naturais devem ser ensinados para que suas especificidades sejam compreendidas de forma sistêmica, apreendendo toda sua complexidade, resultando em aprendizagens aplicáveis à resolução de questões cotidianas ou profissionais. Visando sensibilizar os educadores para a importância da adoção de um paradigma científico complexo, dois recursos didáticos foram utilizados em uma sequência de atividades: esquemas baseados em mapas conceituais (ECMC) e mídia televisiva. No primeiro encontro os grupos elaboraram esquemas sob a seguinte questão norteadora: "Qual a sua visão de Ciência?". No segundo encontro, analisaram o episódio "O Princípio de Occam", da série House MD e elaboraram novos esquemas. As relações estabelecidas entre os paradigmas cartesiano, sistêmico e complexo da ciência se estreitaram entre o primeiro e o segundo esquema. Sendo assim, concluímos que instrumentos midiáticos associados a ECMC auxiliam na sensibilização para uma visão complexa da Ciência. Este resultado, não acarreta, necessariamente, mudanças atitudinais, necessitando ações formativas continuadas.

Palavras-chave: Mídia e Educação, Mapas conceituais, Complexidade.

\begin{abstract}
Natural phenomena should be taught so their specificities are comprehended in a systemic perception. All their complexity should be learned in order to achieve applicable results to daily and professional situations. Intending to sensitize educators to the importance of adopting a complex scientific paradigm, two educational tools were used in a sequence of activities: Concept map-based schemata (CMBS) and television media. On first encounter groups constructed schemata following the guiding question: "How do you understand Science?" On a second encounter they analyzed the episode "Occam's Razor" from the series House M.D. then they elaborated new schemata. Connections between Cartesian, systemic and complex paradigms of science became tighter between first and second schemata. As a result was possible to conclude that media instruments associated with CMBS help to sensitize educators to a more complex view of Science. This result doesn't necessarily bring attitude changes, which asks for continued development actions.
\end{abstract}

Keywords: Media and Education, Concept maps, Complexity. 


\section{Introdução}

Os fenômenos naturais têm sido objeto de curiosidade para a humanidade, que ainda busca compreendê-los e decifrá-los. Os questionamentos iniciais remetem à Filosofia grega, evoluindo na Idade Média e no lluminismo por diferentes abordagens, seja numa perspectiva religiosa/sobrenatural, seja pela "lógica aplicada", ou seja, as teorias científicas. É inegável o desenvolvimento de muitas áreas conceituais a partir de uma Ciência cartesiana/newtoniana e de caráter positivista. Entretanto, o reducionismo do modelo cartesiano/newtoniano estimulou a fragmentação de um todo a ser estudado, reduzindo-o às suas partes constituintes e verticalizando o seu estudo. $O$ pressuposto era de que este percurso seria suficiente para naturalmente permitir a compreensão do todo original (CHALMERS, 1993; MARIOTTI, 2008).

Tal perspectiva refletiu-se na estrutura escolar desde o Ensino Fundamental até o Superior. A “divisão" do conhecimento em áreas disciplinares bem delimitadas favoreceu a hiperespecialização fragmentada e o enciclopedismo que se materializam associadas a uma prática de ensino tradicional (CARNEIRO-LEÃO et al., 2010; BEHRENS, 2006).

Portanto, ao longo de nossa formação escolar, acostumamo-nos a identificar e explicar um dado fenômeno natural sob uma única perspectiva seja da Física, da Química ou da Biologia. Entretanto, será que cada uma dessas perspectivas, tomada isoladamente, é suficiente para que se compreenda o tal fenômeno como um todo integrado? Na verdade, em certo momento percebemos a necessidade de restabelecer a articulação dos saberes, pois é praticamente impossível a explicação de muitos fenômenos sem a articulação de diversas áreas.

Para Morin (2003, p. 41):
"A hiperespecialização impede tanto a percepção do global (que ela fragmenta em parcelas), quanto do essencial (que ela dissolve). Impede até mesmo tratar corretamente os problemas particulares, que só podem ser propostos pensados em seu contexto. Entretanto, os problemas essenciais nunca são parcelados e os problemas globais são cada vez mais essenciais."

Segundo Morin (2003) o todo tem qualidades ou propriedades que não são encontradas nas partes, se estas estiverem isoladas umas das outras, e certas qualidades ou propriedades das partes podem ser inibidas pelas restrições provenientes do todo. Nessa época, Morin apontava para essa inadequação, ressaltando haver um abismo entre os saberes desunidos, divididos, compartimentados e a realidade (problemas cada vez mais multidisciplinares, transversais, multidimensionais, transnacionais, globais e planetários). O conhecimento do mundo como $o$ mundo é uma necessidade ao mesmo tempo intelectual e vital. Diante dessa afirmação, o autor discorre sobre o grande problema atual da humanidade: como ter acesso às informações sobre o mundo e como ter a possibilidade de articulá-las e organizá-las? Como perceber e conceber o Contexto, o Global (a relação todo/partes), o Multidimensional, o Complexo?

138 DOI: Em andamento.

R. Bras. de Ensino de C\&T 
Em paralelo, o físico David Bohm influenciou os trabalhos de outros físicos e filósofos que acreditam na conectividade dos eventos e dos elementos e no impacto positivo que esse paradigma pode ter para a Ciência e para o seu ensino e, com o seu trabalho, intenta abrir o diálogo entre as ciências sociais, as ciências humanas e a física. Nesse sentido, propõe uma nova perspectiva para olhar a realidade, afirmando que:

"A tarefa da ciência é derivar as partes abstraindo-as do todo, explicando-as como aproximadamente separáveis, estáveis e recorrentes; porém, elementos externamente relacionados formam sub-totalidades relativamente autônomas, que devem ser descritas em termos de uma ordem explicada." (BOHM, 2001, p. 235).

Silva et al. (2014) acreditam que para a formação de conceitos em consonância com o paradigma sistêmico, se faz necessária uma articulação entre diferentes teorias que possa servir de base para a compreensão dos fenômenos, a partir do estudo de suas partes e sob diferentes contextos. Portanto, é pertinente assumir uma nova postura diante da Ciência e do ensino das Ciências, definindo e reposicionando os conceitos de Sistemicidade, Complexidade e Cartesianismo.

Uma educação articulada que permita a construção de conceitos para formar cidadãos conscientes exige, no mínimo, o repensar dos paradigmas que estão na base daqueles envolvidos no processo ensino-aprendizagem, desde o próprio aprendiz, até cientistas e governantes. Ter direito à educação é uma premissa de todos os países do mundo, mas a qualidade dessa educação precisa ser amadurecida, tendo em vista a inserção crítica do indivíduo na realidade política e científico-tecnológica da atualidade.

Para Morin (2003, p. 38) o pensamento pertinente deve enfrentar a complexidade. Para ele:

"Complexus significa o que foi tecido junto; de fato há complexidade quando elementos diferentes são inseparáveis constitutivos do todo (como o econômico, o político, o sociológico, o psicológico, o afetivo, o mitológico), e há um tecido interdependente, interativo e inter-retroativo entre o objeto de conhecimento e seu contexto, as partes e o todo, o todo e as partes, as partes entre si."

Segundo Morin (2001), o pensamento complexo deve operar a rotação da parte ao todo, do todo à parte, do molecular ao molar, do molar ao molecular, do objeto ao sujeito, do sujeito ao objeto. Silva et al. (2014, p. 23) complementam:

"O pensamento complexo, por sua vez, é capaz de compreender a complexidade dos fatos, pois lida tanto com a "ordem" quanto com a "desordem", pois não existe percepção apenas objetiva ou exclusivamente

R. B. E. C. T., vol 8, núm. 1, jan-abr.2015 ISSN - 1982-873X

DOI: Em andamento. 
subjetiva. Em outras palavras, é necessária uma complementaridade entre a linearidade e a sistemicidade, entre o reducionismo e o holismo, entre a análise e a síntese para ser capaz de perceber a complexidade das coisas."

Partilhando do pensamento de Silva (2011), o presente trabalho destaca a importância dos pontos de vista cartesianos e sistêmicos e da relação entre eles nos momentos complexos vividos durante a pesquisa. O que importa aqui é a utilização de uma metodologia, contextualizada, baseada na articulação de ideias e pessoas e que permita o debate sobre as óticas específicas, porém de forma interligada.

Neste sentido, Marx e Engels (1999), afirmam que o conhecimento científico-tecnológico e, por extensão, os equipamentos tecnológicos estão disponíveis e podem aliviar a população humana do fardo pesado do trabalho, da ignorância, das crenças, da fome, da miséria e da opressão. Segundo esses autores, se a população ainda não tem acesso a esse conhecimento científico e se este não faz parte do seu universo cultural, não é sua culpa ou sequer da ciência e da tecnologia. Levando-se em conta que nenhuma dessas é neutra, pode-se especular quanto à falta de políticas públicas mundiais de reinvenção e de incorporação desse conhecimento pela comunidade humana.

Mariotti (2008) afirma que, embora aparentemente antagônicos, o pensamento sistêmico não é independente do linear, posto que ambos possam conviver de forma complementar. Bohm (2001), por outro lado, coloca a importância da inseparabilidade, uma vez que, para ele, há a necessidade de se ter uma visão global do mundo e afirma:

"O conteúdo do fato observado não pode ser coerentemente visto como separado dos modos de observação, da instrumentação e dos modos de entendimento teórico". (BOHM, 2001, p.193).

Fica claro que a especificidade não pode ser esquecida e o método científico precisa levar em consideração aspectos que insiram o objeto ou sujeito de estudo em um contexto. É importante perpassar por uma perspectiva cartesiana, desde que esta não seja única em uma metodologia ou que a visão do todo apareça em detrimento da visão fragmentada. Sendo assim, cabe adotar uma postura que crie um ponto de interseção entre a postura cartesiana e a sistêmica, viabilizando a complexidade (Figura 1). 


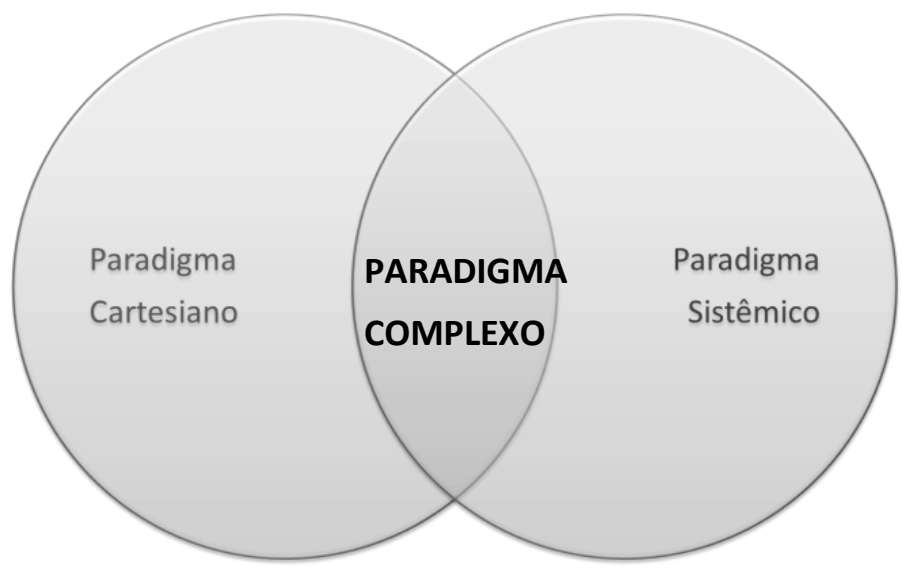

Figura 1 - Diagrama demonstrando a inter-relação entre os paradigmas Cartesiano, Sistêmico e Complexo

(Fonte: Diagrama elaborado pela autora)

Algumas ferramentas podem e devem ser usadas no sentido de efetivar o ensino voltado para o pensamento complexo. Na presente pesquisa, foram escolhidos os Esquemas baseados na proposta dos Mapas Conceituais (ECMC) e a mídia televisiva. Os mapas conceituais (MC), propostos por Novak $(1977,1998)$ são ferramentas largamente utilizadas para explicitar a estrutura conceitual dos indivíduos, convidando-os a repensar princípios e suas respectivas articulações, sendo bastante úteis para o ensino e avaliação da aprendizagem e na análise do conteúdo curricular (MOREIRA, 2006, 2013; RUIZ-MORENO et al., 2007). Posteriormente, Novak e Cañas (2010) propuseram algumas modificações como o "estacionamento" de conceitos (parking lot, no original). Neste trabalho, para atender a perspectiva de paradigmas não lineares e atender aos objetivos da presente pesquisa, introduzimos as seguintes modificações na proposta de Novak e Cañas: (1) permitir a repetição de conceitos; (2) desconsiderar a hierarquia linear de distribuição conceitual; (3) aceitar o uso de substantivos ou adjetivos dentro dos quadros (com importância equivalente de conceitos); linhas sem setas ou uso de setas em duplo sentido, enfatizando uma relação de reciprocidade; (4) "quadro de conceitos", quando conceitos podem ser apresentados no interior de um quadrado ou um círculo, com relação próxima, mas nem sempre clara; e (5) não obrigatoriedade do uso de conectores ou frases de ligação.

Nesse contexto, a mídia televisiva pode ser utilizada para a introdução, aprofundamento ou enriquecimento de conceitos, por apresentar elementos instigadores para as discussões de diversos temas e em vários níveis de aprendizagem, desde que bem planejado (ROCHA et al., 2010). Alguns seriados têm desenvolvido argumentos que permitem uma contextualização adequada a questões consideradas áridas e abstratas em sala de aula, além de estabelecerem uma via lúdica de comunicação com a turma. Um exemplo é a discussão da origem do conhecimento e dos paradigmas da Ciência, como referido. Por este motivo, a popularidade do anti-herói Gregory House, protagonista do seriado House MD (FOX, 2004-2012) favorece uma 
discussão sobre o Conhecimento e sobre a vivência/aplicação dos paradigmas sistêmico e complexo. $O$ contraponto cartesiano a este personagem é a sua equipe de especialistas, os quais raciocinam em função de suas perspectivas.

Corroborando com Morin (2003), quando diz que a educação deve promover a "inteligência geral" apta a referir-se ao complexo, ao contexto, de modo multidimensional e dentro da concepção global, o objetivo deste trabalho é investigar o potencial de uma sequência de atividades didáticas baseada na reflexão, ação e interação e uso da mídia televisiva, em provocar rupturas paradigmáticas nas concepções de Ciência de professores e futuros educadores.

\section{Material e Métodos}

A pesquisa desenvolvida neste trabalho é de cunho qualitativo, ou seja, valoriza aspectos subjetivos como as inter-relações entre situações, instrumentos de pesquisa e sujeitos. No seu desenvolvimento foram realizados dois encontros intercalados por uma pausa para análise dos dados e preparação da sensibilização.

\section{Participantes da Pesquisa}

Foram convidados para participar de um momento de discussão sobre suas concepções de Ciência, licenciandos e egressos do Programa de Pós-Graduação em Ensino das Ciências. A habilitação em área específica não era um fator limitante, pois o objeto de estudo é a discussão sobre os paradigmas cartesiano, sistêmico e complexo, sem apresentar, neste momento, conteúdos específicos disciplinares relevantes. A exigência era a de participação nos dois encontros. Sendo assim, o grupo foi formado por cinco participantes, organizados de acordo com seu grau de formação: Mestres ( $\underline{\mathbf{M}} ; \mathrm{n}=2)$ e Licenciandos $(\underline{\underline{L}} ; \mathrm{n}=3)$.

\section{Etapas percorridas}

I Etapa - Levantamento das Concepções Prévias (LCP): Nesse momento houve uma conversa inicial para explicação de como seriam os dois encontros, além do estabelecimento de acordos quanto a horários e datas. Em seguida, os sujeitos elaboraram, nos subgrupos citados $(\mathrm{M}$ e $\mathrm{L}$ ), seus esquemas conceituais (ECMC-1). Receberam um envelope com as seguintes palavras: Matemática, Humanas, Ambiente, Filosofia, Cidadãos, Ambiente Escolar, Método Científico, Sistêmica, Transposição, Cartesiana, Didática, Complexidade, Ciência, Fenômenos, Exatas, Conceitos, Conhecimento, Conscientes e ainda seis etiquetas "coringa" para escrever o que julgassem necessário. A questão norteadora para a elaboração dos esquemas conceituais foi “Qual a sua visão da Ciência?”. Após a produção, estes foram socializados. Esta primeira etapa teve uma duração de três horas das quais, aproximadamente, duas horas foram usadas para a elaboração e socialização do LCP.

142 DOI: Em andamento. 
II Etapa - Momento de análise dos esquemas do LCP e preparação do segundo encontro de acordo com os resultados obtidos: Os ECMC-1 foram analisados a partir de cinco categorias estabelecidas pela pesquisadora em trabalho anterior (CORDEIRO et al., 2010). O Quadro 1, a seguir, traz as categorias e a colaboração individual para a presente pesquisa. 
Quadro 1 - Categorias de análise dos Esquemas baseados em Mapas Conceituais e perguntas que ajudaram a identificá-las

\begin{tabular}{|c|c|c|}
\hline CATEGORIA & DESCRIÇÃO DA CATEGORIA & QUESTÕES NORTEADORAS \\
\hline I & $\begin{array}{l}\text { Fragmentação quanto à distribuição } \\
\text { dos conceitos apresentados no } \\
\text { esquema. }\end{array}$ & $\begin{array}{l}\mathrm{O}(\mathrm{s}) \text { autor (es) apresentam uma visão } \\
\text { articulada da Ciência? Como os conceitos } \\
\text { são distribuídos no esquema? }\end{array}$ \\
\hline II & Epistemologia da Ciência. & $\begin{array}{l}\mathrm{O}(\mathrm{s}) \text { autor (es) reconhecem ou citam a } \\
\text { origem da Ciência? }\end{array}$ \\
\hline III & Principais relações entre os conceitos. & $\begin{array}{l}\text { As relações estabelecidas são claras? Os } \\
\text { autores reconhecem a relação entre as } \\
\text { Ciências Humanas e Exatas? }\end{array}$ \\
\hline IV & $\begin{array}{l}\text { Visão sistêmica e/ou complexa } \\
\text { expressa em conceitos, quadros } \\
\text { conceituais, conectores ou setas. }\end{array}$ & $\begin{array}{l}\mathrm{O}(\mathrm{s}) \text { autor (es) reconhecem a possibilidade } \\
\text { de outras visões além da cartesiana? }\end{array}$ \\
\hline V & $\begin{array}{l}\text { Aplicabilidade cotidiana e/ou escolar } \\
\text { dos conceitos. }\end{array}$ & $\begin{array}{l}\mathrm{O}(\mathrm{s}) \text { autor (es) identificam a influência que a } \\
\text { Ciência e a construção de conceitos } \\
\text { científicos exerce sobre o entendimento da } \\
\text { vida e dos fenômenos naturais? }\end{array}$ \\
\hline
\end{tabular}

(Fonte: dados organizados pela autora)

Com relação à mídia, o terceiro episódio da 1ạ Temporada do seriado estadunidense House MD (Razor of Occam) foi editado, excluindo-se a primeira cena considerada sem importância para o objetivo da pesquisa. Após a avaliação dos primeiros esquemas conceituais (ECMC-LCP), o episódio editado foi analisado, selecionando-se três cenas e elaborando-se as questões norteadoras apresentadas no Quadro 2, por ordem de exibição: 1- episódio; 2- cena A; 3- cena B e 4- cena C. 
Quadro 2 - Caracterização das cenas selecionadas para nova exibição e suas respectivas questões norteadoras

\begin{tabular}{|c|c|c|c|}
\hline Cena & Breve descrição & Tempo* & Questionamentos \\
\hline $\begin{array}{l}\text { Episódio } \\
\text { editado }\end{array}$ & $\begin{array}{l}\text { A primeira cena não } \\
\text { contribui para o objetivo da } \\
\text { pesquisa e foi excluída. o } \\
\text { episódio narra o } \\
\text { aparecimento de um } \\
\text { conjunto de sintomas em um } \\
\text { rapaz que não aparentava } \\
\text { fazer parte de uma única } \\
\text { patologia. De acordo com o } \\
\text { princípio de Occam, alguns } \\
\text { sintomas fariam parte de } \\
\text { uma patologia e os demais } \\
\text { seriam aleatórios. }\end{array}$ & $\begin{array}{l}\text { 00:38:38 } \\
\text { (TOTAL) }\end{array}$ & $\begin{array}{l}\text { Quais cenas chamaram mais a sua } \\
\text { atenção? Por quê? } \\
\text { Você consegue identificar momentos } \\
\text { onde os personagens articulam } \\
\text { informações? } \\
\text { Você percebe uma postura fragmentada } \\
\text { em alguma cena? } \\
\text { Teve algo no episódio que, para você, } \\
\text { não ficou claro? }\end{array}$ \\
\hline Cena A & $\begin{array}{l}\text { House conversa com os } \\
\text { pacientes na sala de espera } \\
\text { do ambulatório. }\end{array}$ & $\begin{array}{l}00: 05: 24 \\
00: 06: 50\end{array}$ & $\begin{array}{l}\text { Qual ou quais posturas científicas estão } \\
\text { implícitas no discurso de House? } \\
\text { Justifique! }\end{array}$ \\
\hline Cena B & $\begin{array}{l}\text { House e sua equipe discutem } \\
\text { possíveis diagnósticos. }\end{array}$ & $\begin{array}{l}00: 09: 58 \\
00: 12: 29\end{array}$ & $\begin{array}{l}\text { Qual ou quais posturas científicas estão } \\
\text { implícitas no discurso de House e dos } \\
\text { demais médicos? Justifique! }\end{array}$ \\
\hline Cena C & $\begin{array}{l}\text { House e Wilson discutem um } \\
\text { possível erro médico. }\end{array}$ & $\begin{array}{l}00: 33: 09 \\
00: 34: 25\end{array}$ & $\begin{array}{l}\text { Qual (ou quais) postura(s) científica(s) } \\
\text { está (estão) implícita(s) no discurso de } \\
\text { House e de Wilson? Justifique! }\end{array}$ \\
\hline
\end{tabular}

(*Hora:minuto:segundo; Fonte: Organizado pela pesquisadora a partir do seriado HOUSE MD, 2004, episódio 1x03)

III Etapa - Sensibilização e Levantamento dos Impactos da Sensibilização (LIS): Este momento aconteceu 45 dias após o primeiro encontro. Durou aproximadamente 4 horas. Esta etapa foi subdividida para fins explicativos.

- Exibição do episódio editado. Logo após, os participantes tiveram a oportunidade de expor suas impressões iniciais sobre o episódio, durante cerca de aproximadamente 1 hora;

- Exibição das cenas A, B e C, associadas às questões norteadoras (Quadro 2), seguidas por outro momento de discussão (aproximadamente 1 hora);

R. B. E. C. T., vol 8, núm. 1, jan-abr.2015 ISSN - 1982-873X

DOI: Em andamento. 
- Elaboração dos esquemas conceituais pós-discussão (ECMC-2). Os grupos elaboraram novos esquemas conceituais usando os mesmos kits disponibilizados no primeiro encontro. Este momento final teve duração de aproximadamente duas horas.

IV Etapa - Análise de ECMC-1 e ECMC-2 a partir das cinco categorias de análise, das socializações dos esquemas e das explicações verbais dos participantes videogravadas durante os encontros. Os passos metodológicos desenvolvidos estão ilustrados esquematicamente na Figura 2.

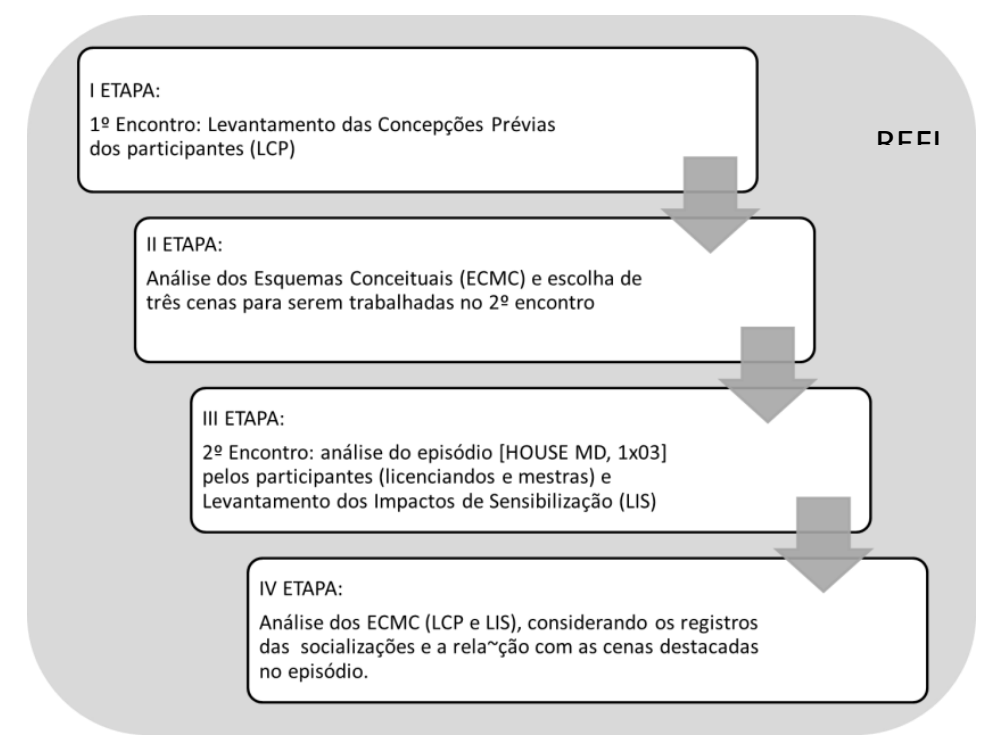

Figura 2 - Fluxograma resumindo as etapas da pesquisa mergulhada em um universo de reflexão.

(Fonte: organizado pela pesquisadora)

\section{Resultados e Discussão}

\section{House M.D.: a mídia televisiva como um instrumento de sensibilização}

Cada cena trouxe à tona discussões interessantes que contribuíram para instigar a reflexão acerca das visões cartesiana, sistêmica e complexa. Na cena $A$, descrita no tópico anterior, os sujeitos não entenderam a postura cartesiana de House e mostraram certa revolta pela rejeição que o médico tem aos casos mais simples, como pode ser observado nas falas a seguir:

"Porque a gente não entende essa postura dele de não querer atender os outros pacientes. E ele só se preocupou com aquele caso específico, então nesse ponto eu achei que ele foi cartesiano, porque ele só se preocupou com aquele caso e todo o resto que se dane não interessa a ele, só aquilo. [...] Engraçado, engraçado que assim... Que aquilo ali é o ambulatório, né? Então se trata de casos gerais. E quando ele vai falar ele deixa bem claro a especialidade dele... Eu sou nefrologista e infectologista, então ele deixa 
específico, então tudo que for fora dessa especialidade dele então [...]." [Participante M-2]

A cena B provoca uma discussão interessante sobre a simplicidade do caso e sobre a distribuição dos sintomas feita no quadro por Dr. House. É importante perceber a visão cartesiana de L1, quando, mesmo falando de uma visão do todo, separa as partes:

"Achei interessante quando ele começou a utilizar as cores para sinalizar isso [...] Aí o outro diz, se você for pôr uma cor pra cada doença, as que estão aí não vão ser suficientes. Mas ele quis mostrar que com aquelas possibilidades que ele já tinha apresentado ali estava resolvido o problema, mas eles não tinham identificado a inter-relação das doenças, eles pensavam que... Não... Tudo tem que simbolizar apenas uma coisa, mas várias coisas podem simbolizar várias coisas, ou seja, ele procurou o ponto comum... Como a gente vê na matemática, isso é matemática pura... Eu consegui ver, naquela parte de conjuntos numéricos, ele procurou a interseção dos conjuntos, para poder diagnosticar que não era uma doença, mas duas e através das cores, que é um artifício que os professores utilizam pra gente poder ver essa complexidade de maneira separada, mas tudo voltado para uma maneira sistêmica. Nisso que achei interessantíssimo, que eu consegui associar com a teoria dos conjuntos..." [Participante L-1]

A cena $C$ levanta uma questão mais filosófica, sobre a verdade e surgiram percepções bem diferentes entre os sujeitos, como observado no diálogo a seguir:

"Ele diz que a realidade quase sempre está errada. Eu achei bem forte essa fala. A realidade quase sempre... Porque assim, nem tudo que... Tem muito dessa nova concepção do conhecimento, né? O real, por exemplo, da questão dos sintomas... Que ele tava ali... Será que ele apresentava? Será que é real? É meio filosófico toda essa questão dá pra mergulhar e fazer uma discussão... Mas eu achei bem forte essa frase e acho que a gente... Sei lá..." [Participante M1]

"Eu acho que está muito relacionado à realidade dos fatos de só crer no que vê, que é real. Realidade é o que está na nossa vista... Aquilo em que a gente tá participando... Então o que ele quis dizer mais dessa verdade, porque tudo aquilo que a gente vê, que a gente acha que é real, na verdade não é a realidade, então quase sempre a nossa realidade tá errada, porque por trás daquilo que a gente tá vendo, tem algo a mais, como ela falou... A gente não lê as entrelinhas." [Participante M2] 


\section{Esquemas baseados na proposta de Mapas Conceituais: LIS e LCP, uma análise comparativa}

Ao observar as características gerais do Esquema Baseado na proposta do mapa conceitual (ECMC-1), perceberam-se alguns pontos e características interessantes que colaboram com o diagnóstico da visão sobre Ciência adotada pelos seus autores. A leitura livre desses esquemas, ou seja, a leitura sem o direcionamento por categorias de análise permite observar, por exemplo, o uso de cores diferentes como símbolos.

Sendo assim, a discussão sobre o primeiro esquema dos licenciandos (ECMCL-1; Figura 3) será iniciada a partir das cores utilizadas: o azul e o preto. Este foi organizado em dois blocos pouco articuladas, o que é ressaltado pelo uso de cores diferentes. A cor azul representa o lado das Ciências Exatas, "duras", ou seja, aquela que estuda os fenômenos naturais através do método científico priorizando a separação sujeito-objeto. A cor preta está relacionada às Ciências Humanas, à educação, às pessoas. Essa distinção entre as cores é tão importante, que o grupo a repete em outros momentos, a exemplo das interrogações que relacionam os dois blocos.

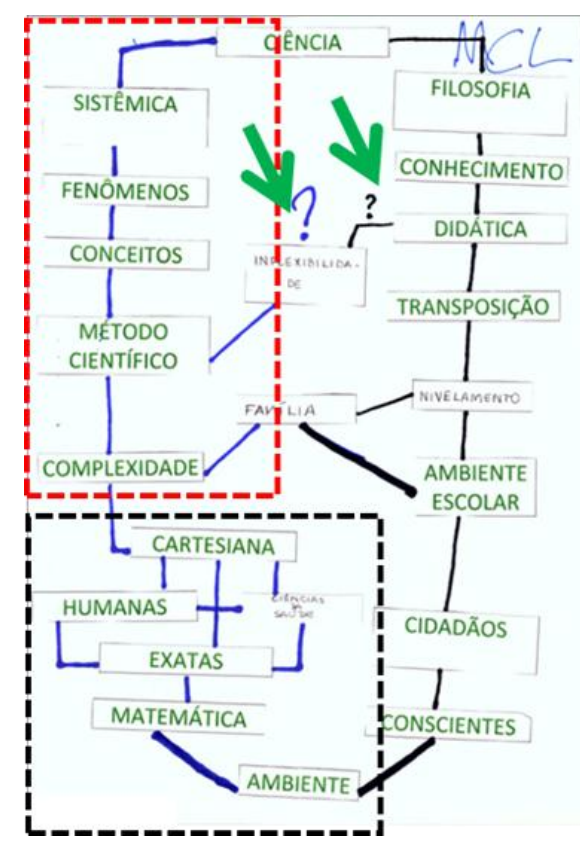

Figura 3 - Esquema baseado na proposta dos Esquemas Conceituais dos Licenciandos 1 (ECMCL-1).

(Fonte: dados coletados pela pesquisadora)

As interrogações apresentam cores diferentes por representarem aspectos também distintos. Pode ser observado que a interrogação relacionada ao Método científico é azul, já o sinal que está entre os conceitos Inflexibilidade e Didática, está escrito em preto. Essa distinção de cores enfatiza ainda mais a dicotomia do mapa. 
Neste ECMCL-1 há uma contradição que não pode deixar de ser discutida: os licenciandos trazem um mapa com dois blocos bem distintos, representando as Ciências Humanas e as Exatas. Entretanto, em um trecho do mapa (Figura 3, no quadrado tracejado em preto), tentam estabelecer uma correlação entre ambas, sugerindo que os elaboradores reconhecem a importância de uma articulação, apesar de não conseguirem expor isso no mapa como um todo. Na realidade, eles estão apenas representando o que chamaram de "pontos cartesianos da Ciência". O Quadro 3 traz o resumo da análise, por categoria, do primeiro esquema elaborado pelos licenciandos. 
Quadro 3 - Análise do ECMCL-1, por categoria.

\begin{tabular}{|c|c|}
\hline Categoria & ECMCL-1 \\
\hline 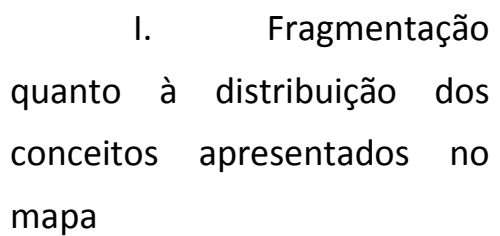 & $\begin{array}{l}\text { Mapa fragmentado. Apesar de cíclico, o mapa está } \\
\text { organizado em dois blocos com quatro conceitos } \\
\text { interligando-os. }\end{array}$ \\
\hline $\begin{array}{l}\text { II. Epistemologia da } \\
\text { Ciência }\end{array}$ & Não fazem referência a Epistemologia da Ciência. \\
\hline $\begin{array}{l}\text { III. Principais relações } \\
\text { entre os conceitos }\end{array}$ & $\begin{array}{l}\text { O mapa está pouco articulado, a maioria dos } \\
\text { conceitos se relaciona apenas com dois outros, um que } \\
\text { chega e um que sai, como causa e consequência. }\end{array}$ \\
\hline $\begin{array}{l}\text { IV. Visão sistêmica } \\
\text { e/ou complexa expressa em } \\
\text { conceitos, } \\
\text { conceituais, conectores ou } \\
\text { setas }\end{array}$ & $\begin{array}{l}\text { Foram utilizados os conceitos Complexidade e } \\
\text { Sistêmica. Os autores também questionaram sobre a } \\
\text { inflexibilidade do método científico e sobre sua relação com } \\
\text { a didática. }\end{array}$ \\
\hline $\begin{array}{l}\text { V. Aplicabilidade } \\
\text { cotidiana e/ou escolar dos } \\
\text { conceitos }\end{array}$ & $\begin{array}{l}\text { O mapa traz os conceitos de Ambiente Escolar, } \\
\text { Ambiente, Didática, Transposição e Família, apesar disso, } \\
\text { esses conceitos não estão articulados. A relação entre eles é } \\
\text { distante e mediada por outros conceitos. }\end{array}$ \\
\hline
\end{tabular}

(Fonte: dados organizados pela pesquisadora)

No segundo esquema dos licenciandos, observa-se que os paradigmas da ciência foram colocados em destaque e relacionados, mesmo que, às vezes, de forma indireta. Esta relação é ilustrada pelo posicionamento centralizado da "visão Sistêmica", entre a "Complexidade" e a "visão Cartesiana" (Figura 4).

A aproximação identificada nesse segundo mapa sugere uma busca pelo esclarecimento dos significados das três visões trabalhadas durante a sensibilização. É importante destacar que o mapa foi iniciado com uma ligação entre Ciência e Filosofia, relação que desemboca no método científico. Só então surgem as três visões, o que coloca o método em uma posição de destaque, como requisito para que as perspectivas que nortearão a produção de conhecimento possam existir.

Outro ponto interessante observado no mapa diz respeito à associação nítida, trazida pelos seus autores, entre as Ciências Exatas e Humanas e suas respectivas visões da Ciência. Os 
licenciandos expõem as seguintes conexões: Complexo e Sistêmico se relacionam às Ciências Humanas, enquanto a visão Cartesiana está associada às Ciências Exatas. Ambas são extremamente lineares, o que está demonstrado na Figura 4, em destaque com as setas vermelha e azul.

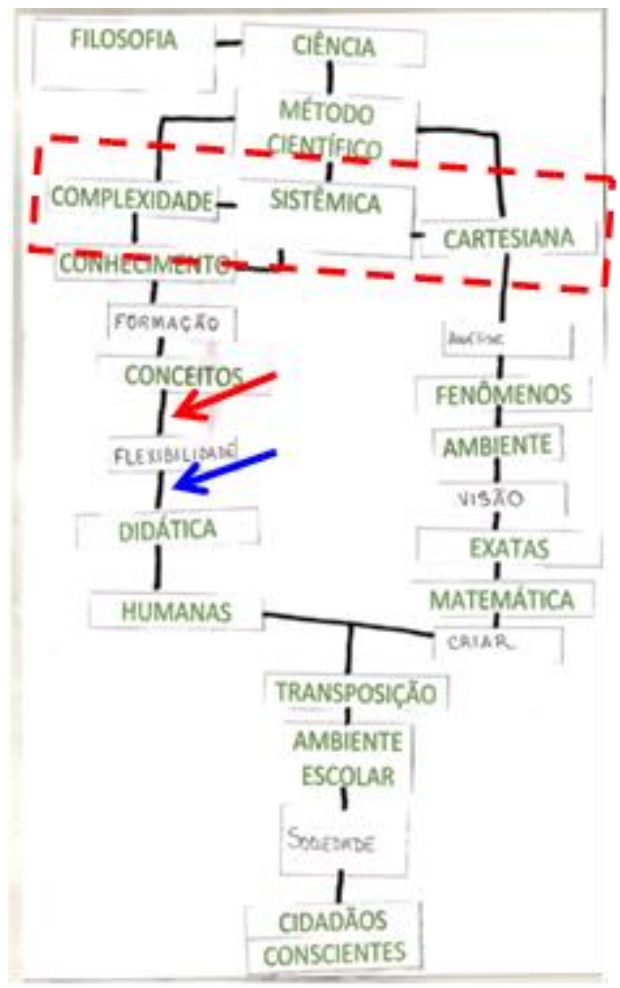

Figura 4 - Esquema baseado no Esquema conceitual dos licenciandos 2 (ECMCL- 2).

(Fonte: dados coletados pela pesquisadora)

Sendo assim, pode-se sugerir que o pensamento exposto no mapa ainda é desarticulado e cartesiano, já que seus autores apresentam relações limitadas entre a Matemática, por exemplo, e o pensamento complexo. O ECMCL-2 ainda manteve a característica fragmentada do ECMCL-1. Observa-se, porém, que a Ciência não foi dividida; ao invés disso, o Método científico foi subdividido, como se abordagens diferentes se fizessem necessárias para cada paradigma.

São identificadas quatro áreas distintas e pouco articuladas. A maioria dos conceitos apresenta duas linhas, uma delas podendo representar uma relação de entrada e outra de saída (Figura 4). Esta separação fica muito clara na apresentação do mapa quando o sujeito L1 relata:

"[...] A gente colocou a ciência através do método científico, mas esse método científico dividido em três sub-métodos ou três correntes que a gente pode destacar: seria a complexa, a sistêmica e a cartesiana [...]". [Participante L1] 
O Quadro 4 traz o resumo da análise do segundo esquema elaborado pelos licenciandos.

Quadro 4-Resumo da análise, por categorias, de ECMCL-2.

\begin{tabular}{|c|c|}
\hline Categoria & ECMCL-2 \\
\hline $\begin{array}{l}\text { I - Fragmentação quanto à } \\
\text { distribuição dos conceitos apresentados } \\
\text { no mapa }\end{array}$ & $\begin{array}{l}\text { Neste mapa observam-se quatro áreas } \\
\text { distintas, pouco articuladas. Sendo assim foi } \\
\text { considerado fragmentado. }\end{array}$ \\
\hline II - Epistemologia da Ciência & $\begin{array}{l}\text { No mapa é observado que a Ciência vem da } \\
\text { Filosofia, numa relação cronológica e de dependência. }\end{array}$ \\
\hline $\begin{array}{l}\text { III - Principais relações entre os } \\
\text { conceitos }\end{array}$ & $\begin{array}{l}\text { Há uma relação entre os blocos do esquema } \\
\text { que não fica clara no mapa, mas que é explicitada } \\
\text { durante a apresentação das produções. }\end{array}$ \\
\hline $\begin{array}{l}\text { IV - Visão sistêmica e/ou complexa } \\
\text { expressa em conceitos, quadros } \\
\text { conceituais, conectores ou setas. }\end{array}$ & $\begin{array}{l}\text { Descrevem uma relação de completude entre o } \\
\text { que é sistêmico e complexo e traz a visão cartesiana } \\
\text { como sendo contrária a essas últimas, porém as } \\
\text { relacionam. }\end{array}$ \\
\hline $\begin{array}{l}\text { V - Aplicabilidade cotidiana e/ou } \\
\text { escolar dos conceitos. }\end{array}$ & $\begin{array}{l}\text { A sociedade deve estar inserida no ambiente } \\
\text { escolar para que a formação de cidadãos conscientes } \\
\text { possa acontecer. }\end{array}$ \\
\hline
\end{tabular}

(Fonte: Dados coletados pela pesquisadora)

As diferenças entre os ECMCL-1 e 2 revelam uma mudança sutil de pensamento. Entretanto, não se pode afirmar que haverá, por parte dos seus autores, uma mudança de perspectiva com relação à Ciência. Os licenciandos reconhecem as diferenças e semelhanças entre a sua primeira produção e o segundo mapa, mesmo que de forma confusa. L1 afirma:
"[...] A gente continuou com a nossa visão ainda hierárquica das ideias. De antemão a gente já pode perceber que houve uma modificação dos nossos pensamentos. Tanto que no nosso primeiro encontro nós utilizamos apenas uma das cartas que ficaram livres para você criar as palavras de ligação... $e$ agora nós utilizamos todas porque nós vimos a necessidade de utilizá-las [...]". [Participante L1]

Analisando os esquemas de forma comparativa (Figura 5), é perceptível na forma de distribuição dos conceitos, uma mudança com relação às visões da Ciência. Esta diferença é considerada, para o presente trabalho, como evolutiva. No ECMCL-1, os autores não relacionam 
as visões, trazendo de forma confusa, uma relação direta entre a Complexidade e o Cartesianismo; em ECMCL-2, os licenciandos trazem uma relação mais clara, com a visão Sistêmica mediando a interação entre a complexidade e a visão Cartesiana.
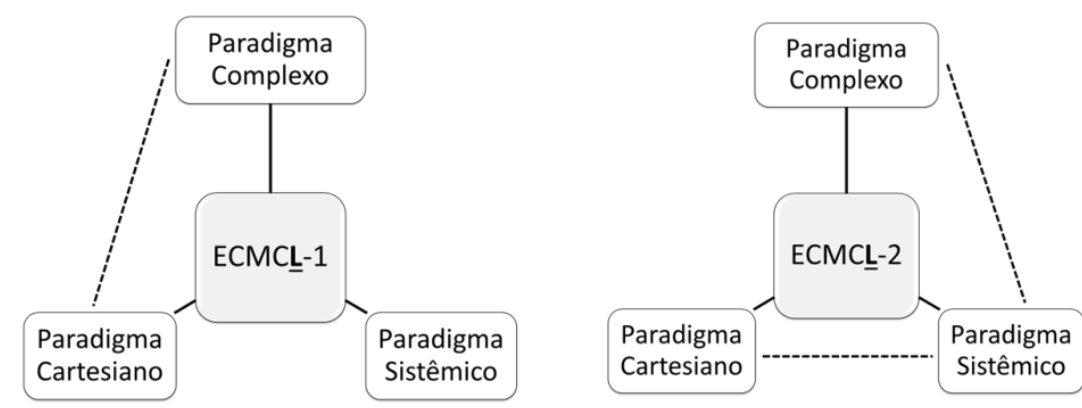

Figura 5 - Diagramas comparativos demonstrando as relações estabelecidas pelos licenciandos nos dois esquemas elaborados durante a pesquisa. (Fonte: dados organizados pela pesquisadora)

As concepções das mestras foram também analisadas. O ECMCM-1 (Figura 6) é apresentado de forma bem articulada. Tal característica deve-se também às inúmeras relações que a maioria dos conceitos carrega e a qualidade exibida por elas. Entretanto, é importante perceber que, apesar das ligações estabelecidas, o mapa apresenta três blocos.

Ainda sobre a estrutura geral do esquema, percebe-se que a sigla IES (Instituições de Ensino Superior) se encontra afastada da dinâmica geral adotada pelas autoras, além de se relacionar com apenas outra palavra - "Conhecimento" (pontilhado marrom). Em paralelo, o fato de estar em uma posição superior no mapa sugere "a superioridade das universidades" e uma posição de distanciamento dos demais setores responsáveis pela educação.

Identifica-se ainda uma distorção do significado de Complexidade. Para explicar esse ponto do esquema, vale a pena destacar o "quadro de conceitos" utilizado pelas suas autoras. Este quadro traz a definição do que entendem por Complexidade, a despeito dos conceitos Sistêmico e Cartesiano não se encontrarem dentro desse quadro, situado em uma região central do esquema e desenhado em azul, destacando-o ainda mais.

Outro ponto interessante é a sequência de relações iniciada com o termo "Conscientes" e finalizada com o conceito "Ambiente" (tracejado vermelho). Pode-se perceber que cidadãos conscientes são capazes de interferir no Ambiente, segundo as autoras, mas existe uma dúvida sobre a formação do cidadão. As mestras deixam os outros cidadãos fora das questões relacionadas ao ambiente, já que estes podem estar (ou não) aptos para interferir no meio em que estão inseridos. Essa relação fica um pouco mais clara no trecho da socialização exposto a seguir: 
"[...] Nessa transposição ela pode criar cidadãos com visão consciente temos uma visão sistêmica, que vislumbra a complexidade ou não, porque ela pode também ser conduzida... Essa transposição de forma cartesiana, sendo cartesiana ela vai fragmentar esse conhecimento, aí ela pode ou não, por isso que eu coloquei essa interrogação, ela pode gerar cidadãos conscientes ou não, se for nessa linha cartesiana, mais fragmentada, mas se for numa linha mais sistêmica vai vislumbrar a complexidade entendendo melhor essa inter-relação destes conhecimentos aqui. Obviamente que esse cidadão consciente irá interferir no ambiente, ele vai entender isso aqui e vai interferir no ambiente." [Participante M2]

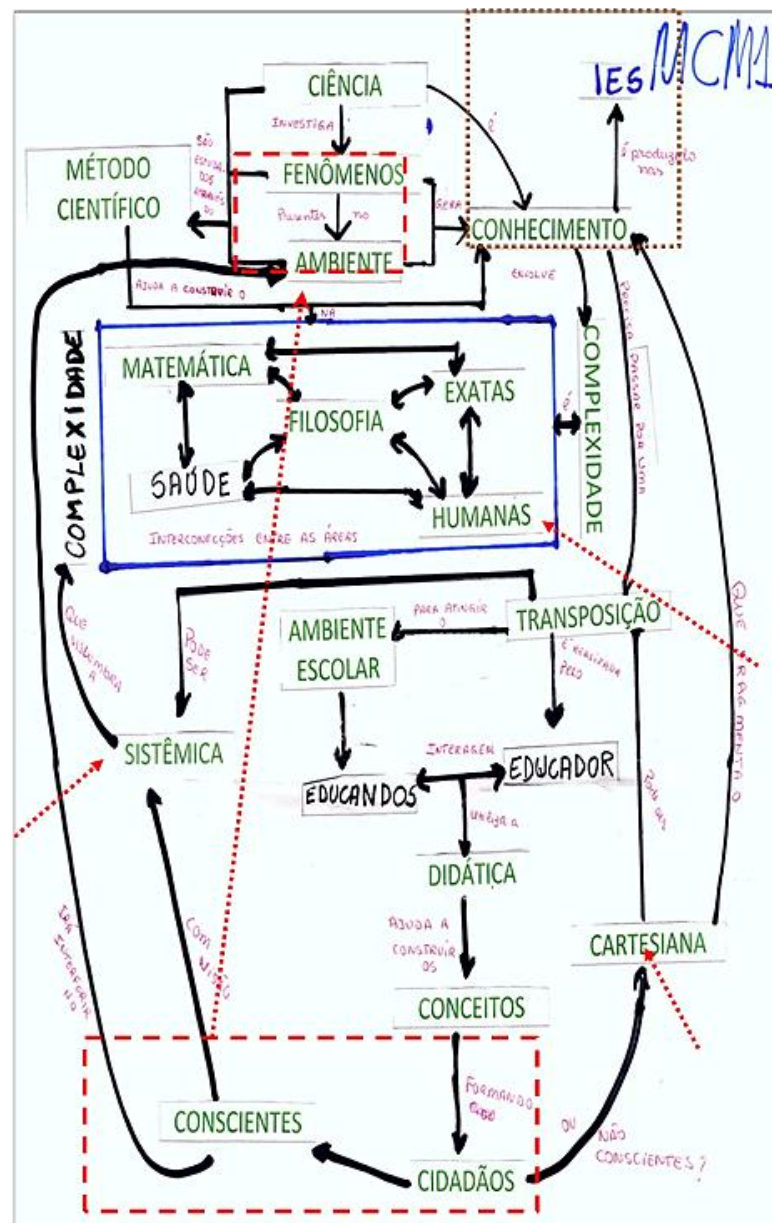

Figura 6 - Primeiro esquema baseado na proposta dos mapas conceituais elaborado pelas mestras (Fonte: dados coletados pela pesquisadora)

Antes de iniciar a análise do ECMCM-1 por categorias vale ainda destacar a relação que as perspectivas sistêmica e cartesiana estabelecem com a transposição do conhecimento. Neste 
caso, o conhecimento pode ser transposto de uma ou outra forma, de forma dicotômica e nunca complementar, contrapondo-se à visão sistêmica. O Quadro 5 , a seguir, traz a análise por categorias do primeiro esquema elaborado pelas mestras.

Quadro 5 - Análise, por categorias, do primeiro esquema elaborado pelas mestras (ECMCM-1)

\begin{tabular}{|c|c|}
\hline Categoria & ECMCM-1 \\
\hline $\begin{array}{l}\text { I. Fragmentação quanto à } \\
\text { distribuição dos conceitos } \\
\text { apresentados no mapa. }\end{array}$ & $\begin{array}{l}\text { Esquema fragmentado, apesar de muito articulado. } \\
\text { A maioria dos conceitos está relacionado com três outros } \\
\text { conceitos, mas as autoras criaram três blocos. Há, também, } \\
\text { o conceito IES que ficou fora da dinâmica do ECMC. }\end{array}$ \\
\hline $\begin{array}{l}\text { II. Epistemologia da } \\
\text { Ciência }\end{array}$ & $\begin{array}{l}\text { A Filosofia é considerada a "mãe" de todas as } \\
\text { disciplinas. }\end{array}$ \\
\hline $\begin{array}{l}\text { III. Principais relações } \\
\text { entre os conceitos. }\end{array}$ & $\begin{array}{l}\text { O uso de setas de duplo sentido em um quadro } \\
\text { conceitual demonstra uma relação de proximidade entre } \\
\text { eles. Há uma relação que condena a visão cartesiana em } \\
\text { detrimento da visão sistêmica, como se existisse uma } \\
\text { completamente correta e a outra fosse totalmente errada. }\end{array}$ \\
\hline $\begin{array}{l}\text { IV. Visão sistêmica e/ou } \\
\text { complexa expressa em conceitos, } \\
\text { quadros conceituais, conectores } \\
\text { ou setas. }\end{array}$ & $\begin{array}{l}\text { Usou os conceitos disponibilizados e ainda repetiu } \\
\text { uma vez o conceito Complexidade. Definiu o que é a } \\
\text { complexidade usando uma relação de seta dupla dentro de } \\
\text { um 'quadro de conceitos'. }\end{array}$ \\
\hline \begin{tabular}{lrl} 
V. & \multicolumn{2}{c}{ Aplicabilidade } \\
cotidiana e/ou escolar dos \\
conceitos.
\end{tabular} & $\begin{array}{l}\text { Usou os conceitos disponibilizados e ainda } \\
\text { acrescentou Educandos e Educadores. }\end{array}$ \\
\hline
\end{tabular}

(Fonte: dados organizados pela pesquisadora)

Em ECMCM-2 pode ser destacada a relação entre as áreas do conhecimento e o método científico. Para as autoras, na perspectiva cartesiana, cada área de conhecimento apresenta sua forma de produção de conhecimento distinta e fragmentada. Outro ponto interessante diz respeito às setas em vermelho, utilizadas pelas autoras, que convergem para a Transposição Didática, realçadas na Figura 7. As autoras convergiram às três visões da Ciência para um ponto em destaque com setas diferentes das demais, a fim de enfatizar a importância da agregação 
dessas visões no momento em que o conhecimento científico é transposto para conceitos escolares. $O$ Quadro 6 resume a análise de ECMCM-2 por categorias.

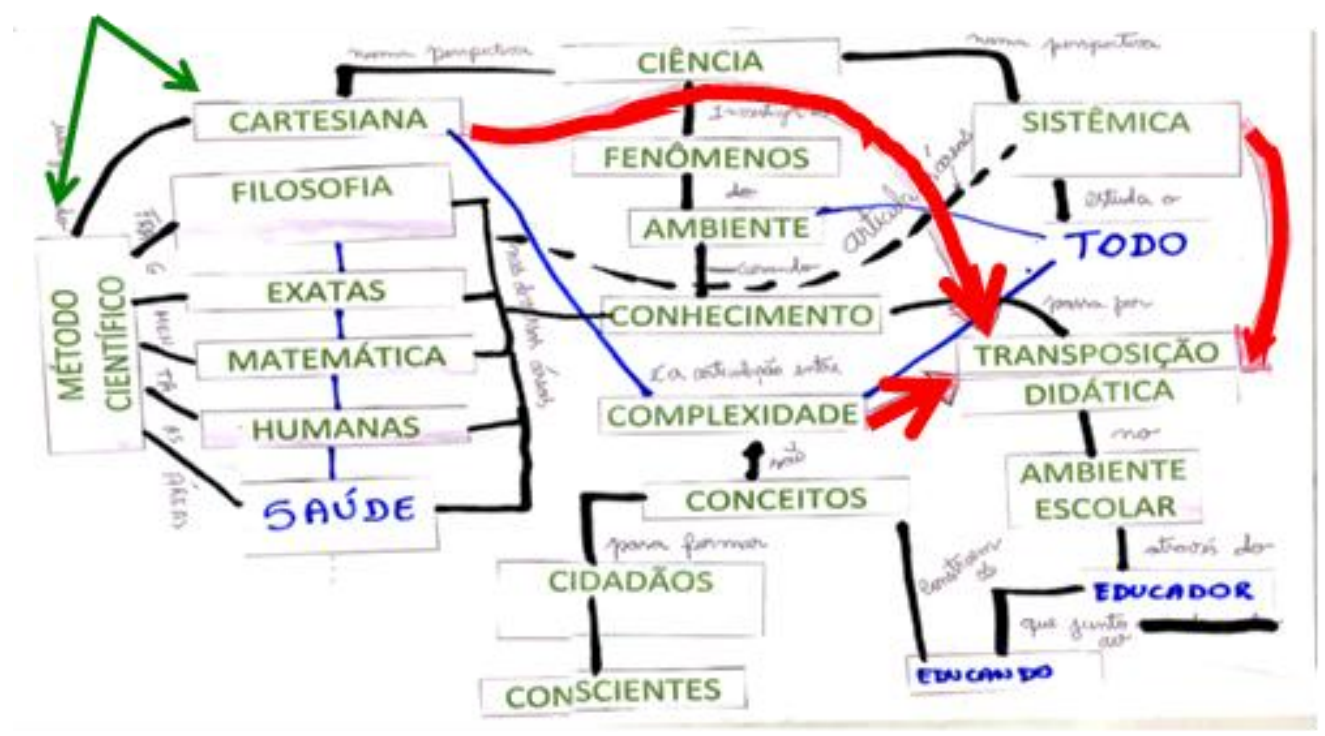

Figura 7 - Segundo esquema baseado em Mapas Conceituais elaborado pelas Mestras (ECMCM-2). (Fonte: dados coletados pela pesquisadora)

Quadro 6 - Resumo da análise de ECMCM-2 por categorias

\begin{tabular}{|c|c|}
\hline Categoria & ECMCM-2 \\
\hline \begin{tabular}{l}
\multicolumn{1}{c}{ I $\quad$ Fragmentação } \\
quanto à distribuição dos \\
conceitos apresentados no \\
mapa.
\end{tabular} & $\begin{array}{l}\text { O mapa apresenta-se muito articulado sendo } \\
\text { considerado não fragmentado apesar da identificação de uma } \\
\text { região com apenas dois conceitos que ficou relativamente fora } \\
\text { da dinâmica do ECMCM- } 2 \text {. }\end{array}$ \\
\hline $\begin{array}{l}\text { II - Epistemologia da } \\
\text { Ciência. }\end{array}$ & $\begin{array}{l}\text { A dupla não contempla esse ponto no seu mapa nem na } \\
\text { sua fala. Colocando a Filosofia como mais uma área do } \\
\text { conhecimento. }\end{array}$ \\
\hline $\begin{array}{l}\text { III - Principais relações } \\
\text { entre os conceitos. }\end{array}$ & $\begin{array}{l}\text { Há dois pontos importantes no mapa: as ligações entre } \\
\text { os conceitos que representam as áreas do conhecimento e o } \\
\text { significado do Todo juntamente com a relação estabelecida } \\
\text { entre ele e os demais conceitos do mapa. }\end{array}$ \\
\hline $\begin{array}{l}\text { IV - Visão sistêmica e/ou } \\
\text { complexa expressa em } \\
\text { conceitos, quadros conceituais, } \\
\text { conectores ou setas. }\end{array}$ & $\begin{array}{l}\text { A interação entre as visões Cartesiana e Sistêmica gera a } \\
\text { visão Complexa. }\end{array}$ \\
\hline
\end{tabular}




\begin{tabular}{|rrr|r|}
\hline V & - & Aplicabilidade \\
cotidiana e/ou escolar dos & $\begin{array}{r}\text { Os conceitos sugeridos foram usados e, acrescidos a } \\
\text { conceitos. }\end{array}$ & $\begin{array}{l}\text { eles, a dupla colocou educandos e educadores, enfatizando a } \\
\text { importância desses atores na formação dos conceitos científicos } \\
\text { e na conscientização dos cidadãos. }\end{array}$ \\
\hline
\end{tabular}

(Fonte: dados coletados pela pesquisadora)

As mestras demonstram mudanças mais acentuadas ao reconhecerem a importância das três visões em prol de uma educação formadora de cidadãos conscientes. É importante ressaltar que no ECMCM-1, as autoras identificam uma relação apenas entre a visão Sistêmica e a Complexa, ao passo que no segundo mapa, as mestras expressam uma relação de completude entre as visões Sistêmica e Cartesiana, tendo como resultado dessa interação, a Complexidade (Figura 8).
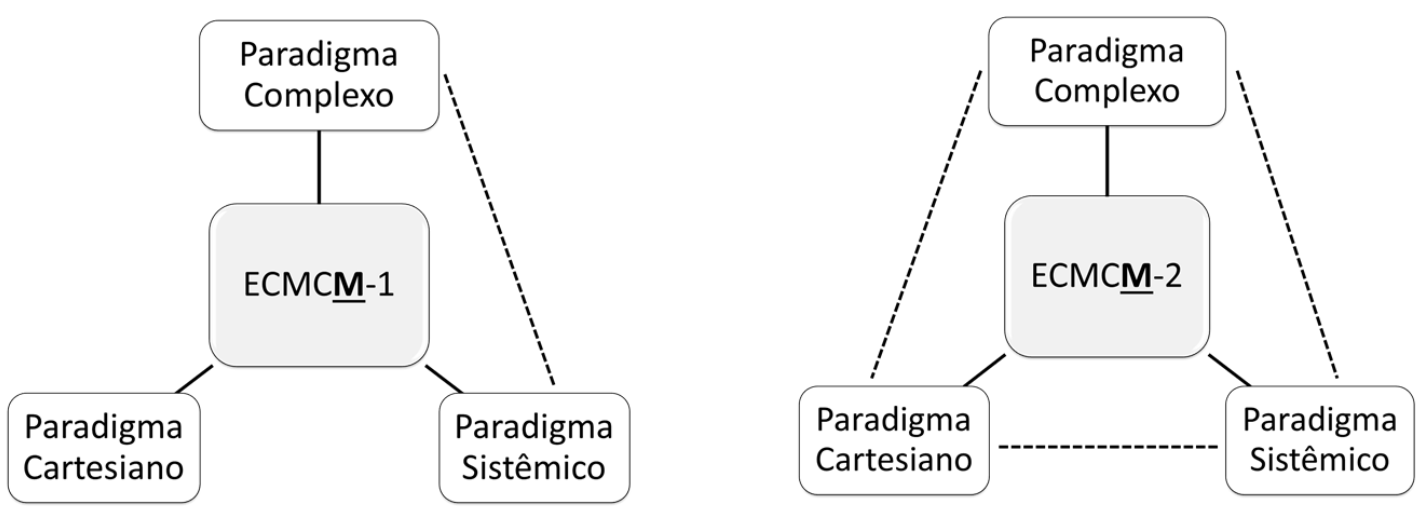

Figura 8 - Relações estabelecidas pelas mestras nos ECMCM-1 e ECMCM-2.

(Fonte: dados coletados pela pesquisadora)

\section{Considerações Finais}

O presente trabalho teve como objetivo sensibilizar mestras e licenciandos quanto a suas percepções sobre o Conhecimento, a Ciência e as disciplinas escolares da área de Ciências Naturais. Segundo Carneiro-Leão et al. (2013), o paradigma de Ciência assumido pelo professor reflete diretamente na sua forma de abordar o conteúdo disciplinar específico e na respectiva prática pedagógica.

No caso dos fenômenos biológicos, tratados de forma contextualizada no seriado House M.D., é possível abordar de forma lúdica as perspectivas paradigmáticas dos personagens. A

DOI: Em andamento. 
equipe de médicos (Foreman, Cameron e Chase) ilustra na prática, como se expressa o paradigma cartesiano/linear, herança da Biologia tradicional. É um viés que se reflete no conteudismo e na memorização. Os conceitos são tratados com tendência à simplificação e busca da causalidade simples e imediata (CARNEIRO-LEÃO et al., 2010). Esses médicos pensam no diagnóstico como simples relações causais: ETIOLOGIA $\rightarrow$ PATOLOGIA $\rightarrow$ DIAGNÓSTICO $\rightarrow$ TRATAMENTO. A partir deste ponto, existe o certo ou o errado, uma escolha que culmina na manutenção da Vida ou na Morte.

O contraponto paradigmático é o protagonista Gregory House, que "pensa fora da caixa" (Tempo). Apesar de ter uma sólida formação especializada, House busca as articulações, procurando entender o todo usando as partes, ou seja, busca compreender a doença a partir da história natural dos sinais e sintomas. Isto caracteriza o paradigma sistêmico na prática. Entretanto, os insights clínicos de House requerem também o conhecimento verticalizado das especialidades, característico de sua equipe médica. A culminância do episódio se dá quando House atinge a complexidade, pela complementariedade necessária entre o conhecimento cartesiano e o sistêmico (MARIOTTI, 2008).

A sequência de atividades utilizada neste trabalho fundamenta-se em três pilares: (1) na reflexão, ação e interação; (2) nas características da mídia televisiva escolhida e (3) em esquemas baseados na proposta dos mapas conceituais (ECMC), utilizados como instrumentos para a coleta de dados.

Os esquemas foram importantes, pois o desenvolvimento metodológico partiu da identificação das percepções e das lacunas dos participantes da pesquisa. O modelo adotado deveria estimular a reflexão e, ao mesmo tempo, ser utilizado como um instrumento de coleta de dados específicos para uma pesquisa qualitativa. Esses esquemas conceituais (ECMC) a partir de um "estacionamento" de conceitos e uma questão norteadora permitiram avaliar a importância ou relevância desses conceitos para os autores do esquema. Pode-se citar ainda que as setas em duplo sentido enfatizam uma relação de reciprocidade, apontando o grau de proximidade e de interdependência dos conceitos envolvidos nessa relação. Além do mais, o aparecimento do "quadro de conceitos" pode sugerir duas questões importantes, porém divergentes: os autores reconheceram uma grande proximidade entre os conceitos do quadro ou ainda têm uma concepção confusa.

Em paralelo, foram identificadas algumas dificuldades para a análise dos dados coletados utilizando-se os ECMC. A subjetividade dos conceitos e das relações estabelecidas requer o uso associado de uma leitura do esquema por seus autores e de entrevistas semiestruturadas, sempre registradas em áudio ou vídeo.

Observar o outro, no desenvolvimento de qualquer atividade, facilita a identificação de erros e limitações daquele que observa, seja um par, seja um personagem ficcional. Nesse ponto 
está a grande contribuição da mídia televisiva para a Educação. No que diz respeito ao Ensino das Ciências, analisar a postura do outro pode favorecer uma identificação paradigmática, com reflexos na prática pedagógica que existe em si.

\section{Referências}

BOHM, D. A totalidade e a ordem implicada: uma nova percepção da realidade. São Paulo: Cultrix, 2001.

BEHRENS, M. A. Paradigma da Complexidade: metodologia de projetos, contratos didáticos e portfólios. Petrópolis, RJ: Vozes, 2006.

CARNEIRO-LEÃO, A. M. A.; SÁ, R. G. B.; JÓFILI, Z. M. S. Formação do pensamento científico no ensino de ciências: a Biologia e suas interfaces como ponto de reflexão. IV Colóquio Internacional Educação e Contemporaneidade. Laranjeiras (SE), 2010.

CARNEIRO-LEÃO, A. M. A.; CARDOSO, S. C. S.; BRAYNER-LOPES, F. M.; JÓFILI, Z. M. S. Os paradigmas científicos de licenciandos de Biologia registrados a partir de um estudo sistêmico sobre os níveis de organização dos seres vivos. Enseñanza de las Ciencias, número extra, p. 689695 , 2013. Disponível em: http://congres.manners.es/congres ciencia/gestio/creacioCD/cd/articulos/art 1229.pdf. Acesso em 12.01.2014.

CHALMERS, A. F. O que é ciência afinal? São Paulo: Brasiliense, 1993.

CORDEIRO, A. R.; SILVA, M. G.; MAYER, M. \& CARNEIRO-LEÃO, A. M. Concepções prévias sobre a disciplina de ciências: mapa conceitual como ponto de partida. III Encontro Nacional de Ensino de Biologia. Fortaleza: SBEnBio, 2010.

HOUSE MD. Criação: David Shore. Emissora de televisão original: FOX, EUA. Intérpretes: Hugh Laurie, Lisa Edelstein, Omar Epps, Robert Sean Leonard, Jennifer Morrison, Jesse Spencer, Olivia Wilde, Peter Jacobson e Kal Penn. Gênero: série médica, drama. Seriado. 8 temporadas. 177 episódios. Exibição original: 16/11/2004 - 25/05/2012. Disponível em <http://pt.wikipedia.org/wiki/House,_M.D>. Acesso em 01/07/2012.

MARIOTTI, H. As paixões do ego: complexidade, política e solidariedade, 3 ed. São Paulo: Palas Athena, 2008.

MARX, K.; ENGELS, F. A ideologia alemã. 11. ed. São Paulo: HUCITEC, 1999.

MOREIRA, M. A. Mapas conceituais e diagrama V. Porto Alegre: Ed. do autor, 2006.

MOREIRA, M. A. Aprendizagem significativa em mapas conceituais. Textos de Apoio ao Professor de Física, PPGEnFis/IFUFRGS, v. 24, n. 6, 2013. 
MORIN. E. Os sete saberes necessários à educação do futuro. 8. São Paulo: Cortez, 2003.

MORIN, E. O Método II: a vida da vida. Porto Alegre: Sulina: 2001.

NOVAK, J. D. A theory of education. Ithaca, NY: Cornell University Press, 1977.

NOVAK, J. D. Learning, creating, and using knowledge: concept maps as facilitative tools in schools and corporations. Mahwah, NJ: Lawrence Erlbaum Associates, 1998.

NOVAK, D. J. \& CAÑAS, J. A. A teoria subjacente aos mapas conceituas e como elaborá-los e usálos. Práxis Educativa, v.5, n. 1, p.09-29. Ponta Grossa: UEPG, 2010.

ROCHA, M. T. L.; DONATO JR., G. F. A.; OlIVEIRA JR., G. I.; MESSEDER, J. C. Sugestões de abordagem para o ensino de ciências: o uso de um seriado de TV. Revista Ciência e Ideias, n. 2. 2010.

RUIZ-MORENO, L.; SONZOGNO, M. C.; BATISTA, S. H. S.; BATISTA, N. A. Mapa conceitual: Ensaiando critérios de análise. Ciência \& Educação, v. 13, n. 3, p. 453-463, 2007.

SILVA, V. F., SÁ, R. B. G., JOFILI, Z. M. S., CARNEIRO-LEÃO, A. M. A. Construção de conceitos sistêmicos através de jogos em busca da flexibilidade cognitiva. IV Encontro Nacional Pesquisa em Ensino de Ciências. Campinas: ABRAPEC, 2011.

SILVA, V. F.; CARNEIRO-LEÃO, A. M. A.; JOFILI, Z. M. S Vamos aprender expressão gênica? Curitiba: Appris, 2014.

Anita Rodrigues Cordeiro. Licenciada em Ciências Biológicas e Mestre em Ensino das Ciências pela Universidade Federal Rural de Pernambuco. Professora da Secretaria de Educação do Estado de Pernambuco. E-mail: anitarcordeiro@gmail.com.

Ana Maria dos Anjos Carneiro-Leão. Médica, mestre em Bioquímica pela Universidade Federal de Pernambuco e Doutora em Ciências (área de concentração Bioquímica) pela Universidade Federal do Paraná. Docente do Departamento de Morfologia e Fisiologia Animal e do Programa de PósGraduação em Ensino das Ciências da Universidade Federal Rural de Pernambuco. E-mail: amanjos50@gmail.com.

Zélia Maria Soares Jófili. Socióloga, mestre em Tecnologia da Educação pelo Instituto Nacional de Pesquisas Espaciais e Doutora em Educação pela University os Surrey (UK). Docente do programa de Pós-Graduação em Ensino das Ciências da Universidade Federal de Pernambuco. E-mail: zjofili@gmail.com.

160 DOI: Em andamento. 